\title{
Biloma during Steroid Therapy for Minimal Change Nephrotic Syndrome
}

\author{
Takayasu Ohtake, Masato Kimura*, Shigeto YoshiI, Naoki Ikegaya, \\ Shigekazu TAKayanagi, Akira Hishida and Eizou KaneKo
}

\begin{abstract}
A 27-year-old man, who had been on steroid therapy for 2 months for his nephrotic syndrome, suddenly developed intra-abdominal bile collection (biloma). He had no previous history of abdominal surgery, trauma, or any disease of the hepatobiliary system. The cause of the biloma formation was due, probably, to cholecystitis in the absence of calculi and a pinhole size perforation in the wall of gall bladder. It was assumed to be closely related to the high-dose steroid therapy over a prolonged period, which would likely suppress the repair process of the locally damaged biliary system.
\end{abstract}

(Internal Medicine 32: 543-546, 1993)

Key words: cholecystitis, echography

\section{Introduction}

The term "biloma" was first introduced in 1979 to describe an encapsulated, extrahepatic collection of bile located outside the biliary tree (1). In most cases, biloma occurs secondary to traumatic injury (1-6), intra-abdominal surgery $(2-5,7-9)$ or iatrogenic procedures, such as percutaneous transhepatic cholangiogram-drainage $(2,3,8,10,11)$. In few cases, biloma occurs "spontaneously" due to gall stones (12), carcinomas (9), and rarely, hepatic infarction $(13,14)$.

Here, we report a case of biloma which occurred during steroid therapy for nephrotic syndrome. In this case, there was no such reason to explain the biloma formation, and it is assumed to be closely related to the patient's steroid therapy.

\section{Case Report}

A 27-year-old Japanese male was admitted on May 24, 1990. He had been suffering from leg edema for 10 days, and the laboratory examination on admission revealed massive proteinuria, $13.1 \mathrm{~g} / \mathrm{day}$, hypoalbuminemia, $2.2 \mathrm{~g} / \mathrm{dl}$, and hypercholesterolemia, $428 \mathrm{mg} / \mathrm{dl}$. Other laboratory data were as follows: RBC $435 \times 10^{4} / \mathrm{ml}$, hemoglobin concentration $14.8 \mathrm{~g} /$ $\mathrm{dl}$, hematocrit $43.2 \%$, WBC $6,300 / \mathrm{mm}^{3}$, platelet $33.9 \times 10^{4} / \mathrm{ml}$, negative CRP, BUN $29 \mathrm{mg} / \mathrm{dl}$, creatinine $1.0 \mathrm{mg} / \mathrm{dl}$, Na 138 $\mathrm{mEq} / \mathrm{l}, \mathrm{K} 4.5 \mathrm{mEq} / \mathrm{l}, \mathrm{Cl} 103 \mathrm{mEq} / \mathrm{l}$, total bilirubin $0.3 \mathrm{mg} / \mathrm{dl}$, SGOT 17 IU/l, SGPT 10 IU/l, LDH 432 IU/l, and alkaline phosphatase $5.1 \mathrm{IU} / \mathrm{l}$. He was diagnosed with nephrotic syn- drome and ultrasound-guided percutaneous renal biopsy was performed on June 6. Briefly, under local anesthesia in the prone position, 18 gauge biopsy-needle (Bard Co., Germany) was used to penetrate his right lower back along a guideline on the panel of ultrasonic tomography to the lower pole of the kidney. Two small pieces of cortical tissue were obtained and histological study revealed minor glomerular abnormality. $\mathrm{He}$ had no reaction to the biopsy, and follow-up ultrasonic echographic studies revealed no abnormal shadow around the kidney or liver. He started oral prednisolone at $40 \mathrm{mg}$ daily from June 22, 1990. By medication, proteinuria was rapidly reduced, but mild proteinuria $(0.3-0.5 \mathrm{~g} /$ day $)$ remained thereafter. Hence the dose of prednisolone was increased to $60 \mathrm{mg} /$ day on July 26 and this dose was maintained for 4 more weeks.

At the end of the second week (August 8) on $60 \mathrm{mg}$ daily prednisolone therapy, he suddenly complained of abdominal pain in the right upper quadrant, and had a fever of $38^{\circ} \mathrm{C}$. Physical examination revealed severe tenderness and slight muscular defense in the right hypochondrial region. The laboratory panel showed WBC of $18,400 / \mathrm{mm}^{3}$, CRP of $10.9 \mathrm{mg} / \mathrm{dl}$, SGOT of $8 \mathrm{IU} / \mathrm{l}, \mathrm{SGPT}$ of $19 \mathrm{IU} / \mathrm{l}$, alkaline phosphatase of 5.2 IU/1, LAP of $41 \mathrm{IU} / 1, \gamma$-GTP of $29 \mathrm{IU} / 1$ and total bilirubin of 0.3 $\mathrm{mg} / \mathrm{dl}$. Abdominal X-ray showed no abnormal findings. Emergent gastrofiberscopy revealed only mild gastric erosions at the anterior wall of the antrum. Ultrasonographic examination of the abdomen demonstrated a hypoechoic lesion of $2 \mathrm{~cm}$ in diameter with some internal echoes, adjacent to the fundus of the gallbladder, the wall of which was slightly thickened (Fig.

From the First Department of Internal Medicine, Hamamatsu University School of Medicine and *Hamamatsu College, University of Shizuoka, Hamamatsu Received for publication January 8, 1993; Accepted for publication June 1, 1993

Reprint requests should be addressed to Dr. Masato Kimura, Hamamatsu College, University of Shizuoka, 3-2-3 Nunohashi, Hamamatsu 432, Japan 

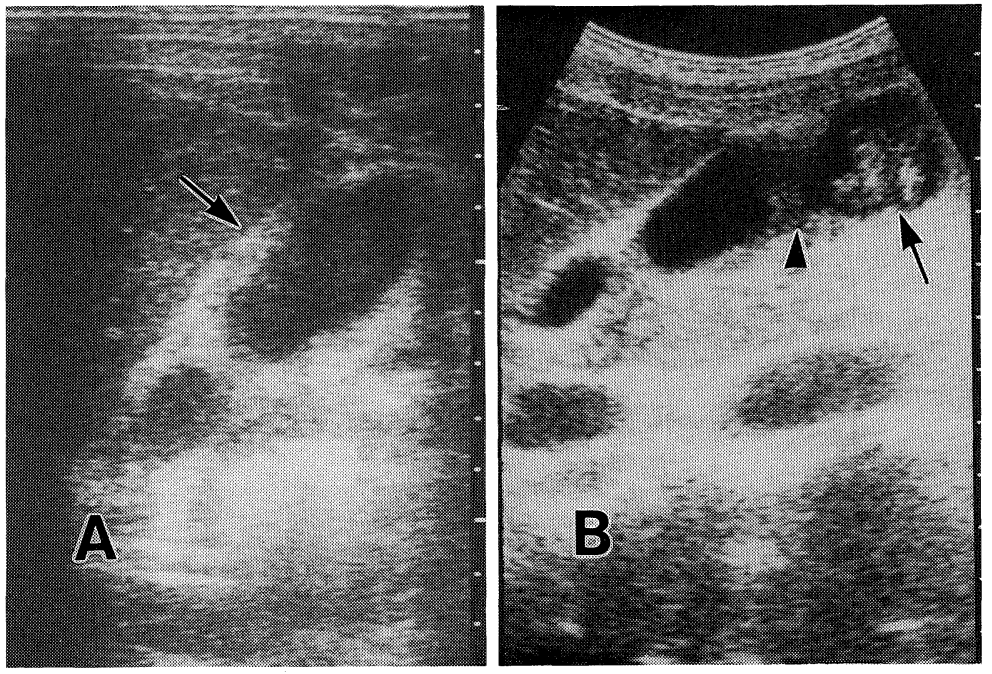

Fig. 1. Ultrasonographies at the onset of abdominal pain and fever. A) Longitudinal sonogram of right lobe of liver and gall bladder. The gall bladder, sectioned on the longitudinal axis, showed slight thickening of the wall (arrow) and contained no stones. B) A hypoechoic lesion measuring $2.2 \times 2.6 \mathrm{~cm}$, which was adjacent to the fundus of gall bladder (arrowhead) and showed some internal echoes in fluid collections (arrow).

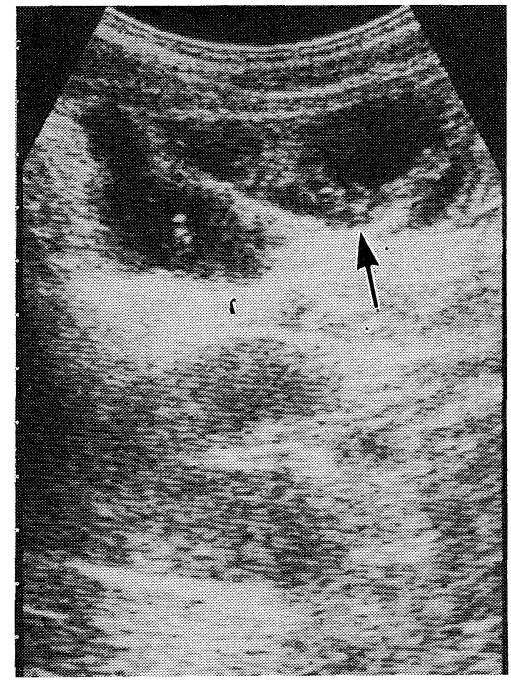

Fig. 2. Ultrasonography at 7 days after the onset of symptoms. The size of the hypoechoic lesion (arrow) peaked at $7.4 \times 3.4 \mathrm{~cm}$.

\section{$1 \mathrm{~A}$ and $1 \mathrm{~B})$.}

Intra-abdominal abscess was suspected and antibiotic therapy was begun. After 2 days, his symptoms and signs of inflammation completely disappeared. But sequential follow-up ultrasonographic studies demonstrated a gradual increase in the size of the lesion. Seven days after the onset of abdominal pain, the size of the hypoechoic lesion reached $7.4 \mathrm{~cm}$ in diameter (Fig. 2), even though antibiotics had been continued during that period. For further evaluation of the properties of the lesion, computer tomography (Fig. 3), barium enema (Fig. 4), and drip

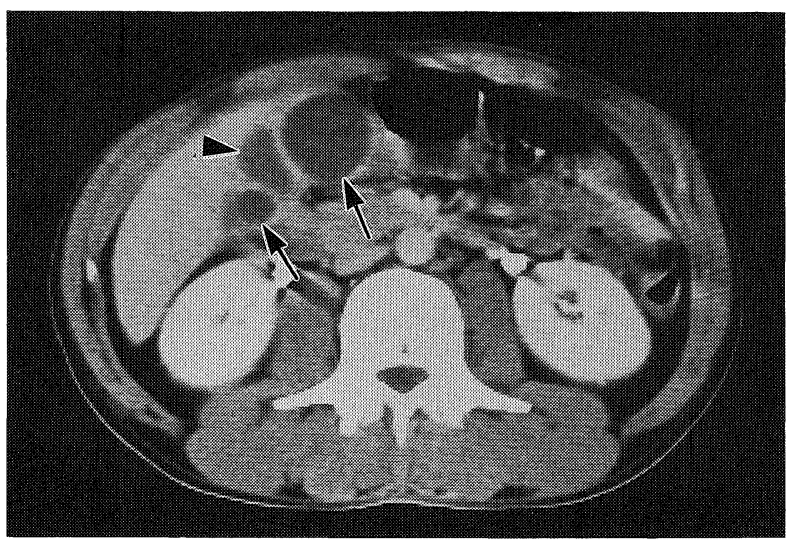

Fig. 3. Computed tomography. Transverse scan $8 \mathrm{~cm}$ inferior to xiphoid process 14 days after the onset. The well demarcated biloma (arrows) surrounded the gall bladder (arrowhead) and contained internal uneven densities.

infusion cholangiography were performed with no useful results to define the origin.

In order to determine the origin of the cystic lesion, echoguided percutaneous transhepatic aspiration of the cyst was performed on October 9. The dark-yellow aspiration fluid contained bile (total bilirubin $12.5 \mathrm{mg} / \mathrm{dl}$, bile acid $14,900 \mathrm{~mol} /$ 1), and was negative on culture. The mass was, therefore, diagnosed as "biloma". To investigate the dynamic intercommunication between the biloma and the biliary system, endoscopic retrograde cholangiography was performed, but no communication of contrast media between them was found. The biloma itself was reduced by continuous drainage for 2 weeks through a percutaneous indwelling catheter (Fig. 5). On 


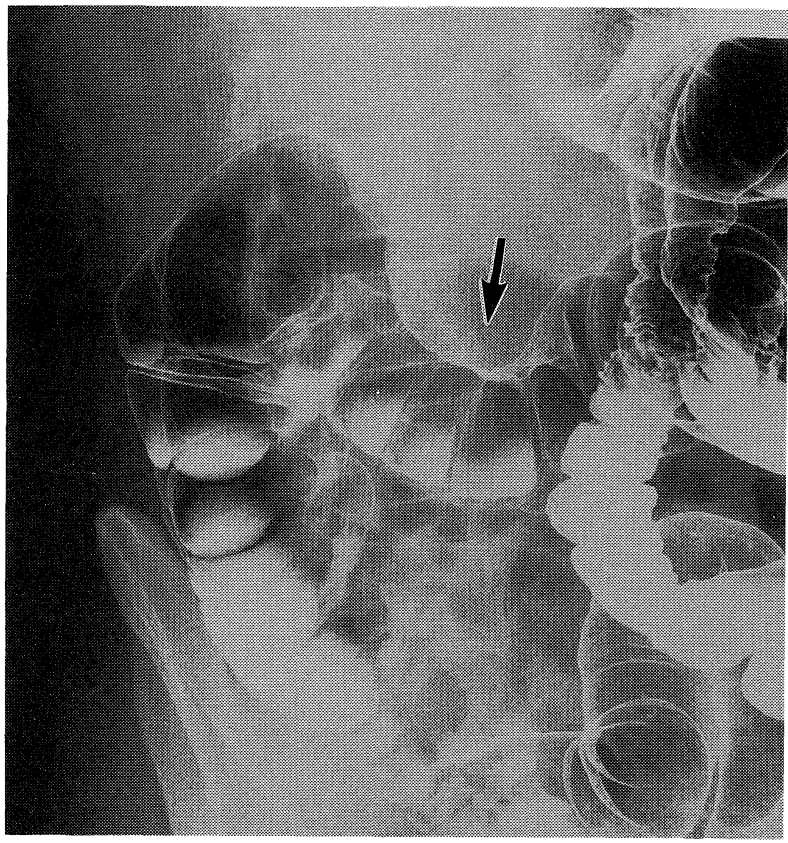

Fig. 4. Barium enema revealed a soft-tissue mass depressing the superior aspect of the transverse colon (arrow). The surface of the colon was smooth 15 days after the onset.

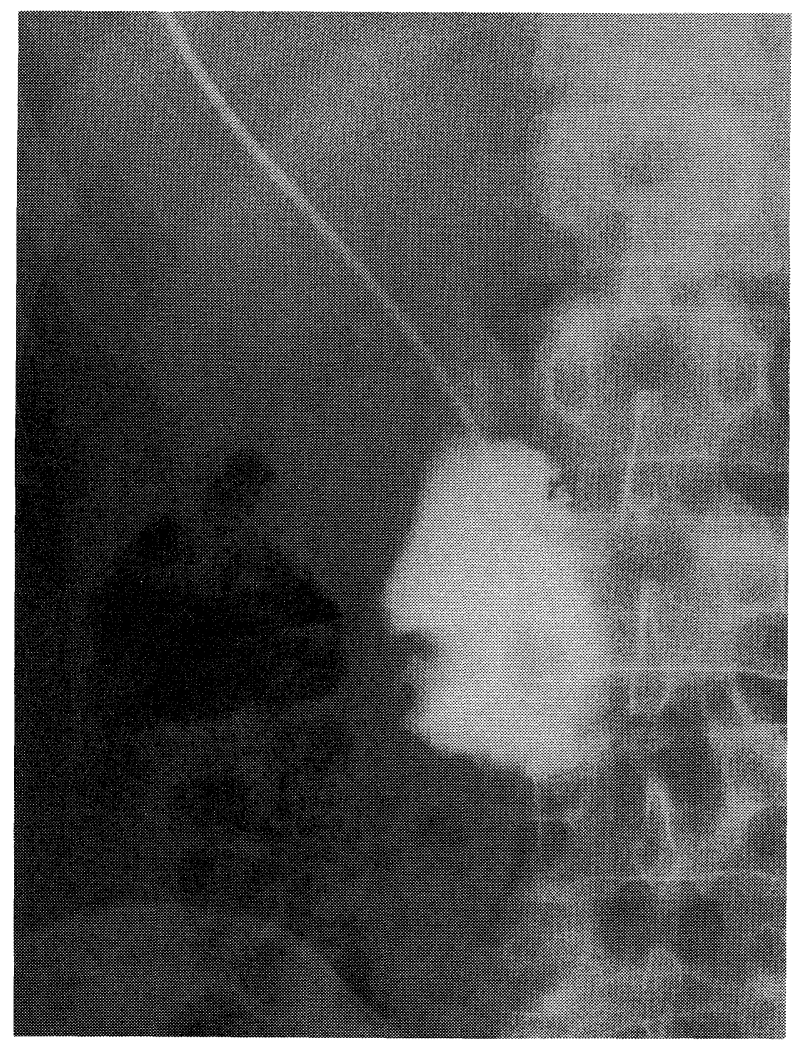

Fig. 5. Contrast study through a percutaneous drainage catheter at 36 days after onset. The inner surface measuring $8.1 \times 5.6 \mathrm{~cm}$ had several irregular projections. follow-up examination, at the time of his discharge one month later, no mass lesion was shown by ultrasonography.

\section{Discussion}

Biloma is caused by iatrogenic (surgical or nonsurgical), traumatic, or spontaneous rupture of the biliary tree (3). The most common cause is abdominal surgery, especially cholecystectomy. Nonsurgical iatrogenic causes of biloma include percutaneous transhepatic cholangiography, liver biopsy, and biliary drainage procedures. This patient had no previous history to explain the formation of a biloma, such as abdominal surgery, trauma or any diagnostic or therapeutic procedure, except a renal biopsy. He had no previous disease in the hepatobiliary system. With regard to ultrasound-guided percutaneous renal biopsy, the procedure was performed successfully and uneventfully and the placement of the tip of biopsy-needle was always controlled; it was not located close to the liver or the gall bladder during the biopsy. In addition, the duration between the time of the renal biopsy and the onset of biloma was too lengthy ( 2 months) to ascribe a direct cause to the biopsy. Repeated ultrasonographic studies following the biopsy did not detect any mass lesion adjacent to the kidney or liver before the onset of abdominal pain. Taken together, it is quite unlikely that the renal biopsy was the causative agent of the biloma formation.

In 1979, Gonsalves (15) reported a case of spontaneous perforation of the gall bladder without calculous disease. The patient had been on prednisolone, $5 \mathrm{mg}$ daily, for 10 years for her rheumatoid arthritis, and the author described the possibility that prolonged steroid therapy might have lowered the resistance of the biliary tree to bacterial invasiveness and also may have suppressed the processes of repair of a locally damaged biliary system.

The present patient did not share any causative factors listed in the reports on biloma since 1979 (Table 1). Although no case in which steroid therapy was ascribed to the cause of biloma has been found in the literature, biloma formation in this case appears to be closely related to steroid therapy. We could not indicate the precise locus of bile leakage. However the thickness of the gall bladder wall, demonstrated by ultrasonography at the onset of abdominal pain, suggested the existence of cholecystitis without gall stones. Sawada et al (12) reported a case of biloma which occurred "spontaneously" due to cholecystitis. In their case, however, the patient had gall stones that could frequently induce cholecystitis and perforation of the gall bladder. From the same reason as described by Gonsalves (15), inflammation of the gall bladder wall, which would have usually been easily repaired, progressed to pin-hole perforations under steroid therapy. Consequently, in spite of the lack of stones, bile leaked outside the gall bladder, induced inflammatory reaction and finally formed biloma.

Acute rupture of the gall bladder generally causes a generalized peritonitis due to the abrupt release of concentrated bile into the peritoneal cavity (16). In some cases, however, low grade leakage of unconcentrated bile from the gall bladder may 
Table 1. Collective Series of Biloma Formation

\begin{tabular}{|c|c|c|c|c|}
\hline \multirow{2}{*}{ Author } & \multicolumn{3}{|c|}{ Cause } & \multirow[b]{2}{*}{ Others } \\
\hline & Operation & Trauma & $\begin{array}{l}\text { Percutaneous } \\
\text { procedure }\end{array}$ & \\
\hline Gould (1) & & 1 & & \\
\hline Kuligouska (2) & 6 & 1 & 2 & \\
\hline Vanquez (3) & 12 & 2 & 4 & \\
\hline Weissmann (4) & 1 & 1 & & \\
\hline Vujic (5) & 1 & 2 & & \\
\hline Esensten (6) & & 5 & & \\
\hline Binmoeller (7) & 2 & & & \\
\hline Mueller (8) & 9 & 1 & 1 & \\
\hline Zegel (9) & 3 & 1 & & $1^{1)}$ \\
\hline Lawson (10) & & & 1 & \\
\hline Johns (11) & & & 1 & \\
\hline Sawada (12) & & & & $1^{2)}$ \\
\hline Middleton (13) & & & & $1^{3)}$ \\
\hline Peterson (14) & & & & $1^{3)}$ \\
\hline & 34 & 14 & 9 & 4 \\
\hline
\end{tabular}

${ }^{1)}$ cancer, ${ }^{2)}$ cholecystitis with gall stone, ${ }^{3)}$ hepatic infarction.

result in a pericholecystic biloma without severe symptoms accompanied by shock (17).

Regarding the diagnosis of biloma, an anechoic/hypoechoic lesion with prominent distal sonic enhancement by ultrasonography is highly likely $(1,2)$. The lesion may contain a small amount of debris or have a few septations. However by ultrasonography or computed tomography, a biloma cannot be distinguished from other cystic lesions. Therefore, the final diagnosis should be made by bile identification in a cyst and/or demonstrating a communication with the biliary tree $(5,8)$. As a procedure to prove the bile communication, an endoscopic retrograde cholangiography or a radionuclide study is usually used. A radionuclide study in particular has been recommended by several authors as a complementary procedure to ultrasound for the evaluation of biloma $(2,4,17)$, because it is not only noninvasive but also it can provide important information regarding the activity of the bile leak and can be helpful in assessing response to treatment with drainage $(4,6)$. Weissmann et al (4) reported a case in which serial ${ }^{99 \mathrm{~m}} \mathrm{Tc}$ HIDA cholescintigraphy revealed obvious diminution of the leak after external drainage. If the biloma in this case would have expanded again after external drainage, reevaluation of the communication with the biliary tree by a radionuclide study might be required.

For treatment, conservative observation often shows in spontaneous shrinkage of the biloma. However, in cases with a large-sized cyst or with infection, percutaneous drainage or surgical intervention may be mandatory. In the present case, we could not find any tendency towards shrinkage of the biloma in 4 weeks. Furthermore, because there was still the necessity for long term steroid therapy for his nephrotic syndrome, we decided to try to elucidate the origin of the lesion in order to avoid recurrence of infection or accidental perforation. Fortunately only one drainage procedure was necessary to accomplish complete resolution of the biloma.

\section{References}

1) Gould L, Patel A. Ultrasound detection of extrahepatic encapsulated bile "biloma". Am J Radiol 132: 1014, 1979.

2) Kuligouska E, Schlesinger A, Miller KB, Lee VW, Grosso D. Bilomas: A new approach to the diagnosis and treatment. Gastrointest Radiol 8: 237, 1983.

3) Vanquez JL, Thorsen MK, Dodds WJ, et al. Evaluation and treatment of intraabdominal bilomas. Am J Radiol 144: 933, 1985.

4) Weissmann HS, Chun KJ, Frank M, Koenigsberg M, Milsten DM, Freeman LM. Demonstration of traumatic bile leakage with cholescintigraphy and ultrasonography. Am J Radiol 133: 843, 1979.

5) Vujic I, Block JG. Biloma: Aspiration for diagnosis and treatment. Gastrointest Radiol 7: 251, 1982.

6) Esensten M, Ralls PW, Colletti P, Halls J. Posttraumatic intrahepatic biloma: Sonographic diagnosis. Am J Radiol 140: 303, 1983.

7) Binmoeller KF, Katon RM, Shneidman R. Endoscopic management of postoperative biliary leaks: Review of 77 cases and report of two cases with biloma formation. Am J Gastroenterol 86: 227, 1991.

8) Mueller PR, Ferrucci JT, Simeone JF, et al. Detection and drainage of bilomas: special consideration. Am J Radiol 140: 715, 1983.

9) Zegel HG, Kurtz AB, Perlmutter GS, Goldberg BB. Ultrasonic characteristics of bilomas. J Clin Ultrasound 9: 21, 1981.

10) Lawson TL. Chronic subcapsular hepatic bile abscess. Am J Gastroenterol 61: 383, 1974.

11) Johns HV. Traumatic cyst of the liver. Br J Surg 468: 57, 1970.

12) Sawada A, Morita K, Yoshida S, et al. A case of biloma after acute cholecystitis. Jpn J Clin Radiol 31: 1057, 1986 (in Japanese).

13) Middleton JP, Wolper JC. Hepatic biloma complicating sickle cell disease. Gastroenterology 86: 733, 1984.

14) Peterson IM, Neumann CH. Focal hepatic infarction with bile lake formation. Am J Radiol 142: 1155, 1984.

15) Gonsalves HJB. Spontaneous perforation of gallbladder due to acute noncalculous ulcerative cholecystitis. JR Coll Surg (Edinb) 24: 159, 1979.

16) Conn JH, Chavez CM, Fain WR. Bile peritonitis: An experimental and clinical study. Am Surg 36: 219-224, 1970.

17) Glenn F. Complications following operations upon the biliary tract. in: Management of Surgical Complications. Saunders, Philadelphia, 1975. 